\title{
VIVENDO ENTRE O PESADELO E O DESPERTAR - 0 PRIMEIRO MOMENTO NO ENFRENTAMENTO DA DIÁLISE PERITONEAL
}

\author{
Living between the nightmare and the awakening - the first time in dealing with \\ peritoneal dialysis \\ Viviendo entre la pesadilla y el despertar -el primer enfrentamiento de la diálisis peritoneal
}

Felipe Kaezer dos Santos ${ }^{1}$

Glaucia Valente Valadares ${ }^{2}$

\begin{abstract}
RESUMO
Este artigo é originado de uma dissertação de mestrado cujo objeto foi o significado do enfrentamento do cliente portador de doença renal crônica mediante o início da diálise peritoneal. Os sujeitos do estudo foram considerados na perspectiva do Interacionismo Simbólico, que valoriza o significado dos elementos do mundo como determinantes para a interação. Seguindo os procedimentos metodológicos da Teoria Fundamentada nos Dados foram instituídos os cinco elementos do paradigma de análise: Causas, Contexto, Fatores Intervenientes, Estratégias de Ação/Interação e Consequências. 0 objetivo desta discussão é conhecer as formas pelas quais o cliente portador de doença renal crônica enfrenta a diálise peritoneal, na iminência de realização deste método. Enfrentando essa nova situação, o cliente parte para um despertar, abandonando a ideia de morte e fazendo uma distinção clara entre a doença renal crônica e a diálise. Se antes as duas percepções pareciam uma só, o despertar apresenta a diálise peritoneal como a "antimorte", como um renascer para a vida.
\end{abstract}

Palavras-chave: Enfermagem. Diálise Peritoneal. Cuidado de Enfermagem

\begin{abstract}
This article originates from a dissertation whose object was the significance of facing the customer carrier of chronic kidney disease by initiating peritoneal dialysis. The study subjects were considered from the perspective of symbolic interactionism, which emphasizes the significance of the elements of the world as determinants for the interaction. Following the methodological procedures of Grounded Theory were established paradigms of the five elements of analysis: Causes, Context, Factors Actors, Strategies for Action/Interaction and Consequences. The purpose of this discussion is finding ways by which the customer carrier faces chronic kidney disease on peritoneal dialysis, on the verge of realizing this method. Facing this new situation, the customer goes to a wake, abandoning the idea of death and making a clear distinction between chronic kidney disease and dialysis. If before, the two perceptions seemed to be just one, the awakening has peritoneal dialysis as the "anti-death" like a rebirth for life.
\end{abstract}

Keywords: Nursing. Dialysis. Nursing Care

\section{Resumen}

Este artículo se origina de una tesis cuyo objeto era el enfrentamiento del cliente portador de enfermedad renal crónica mediante el inicio de diálisis peritoneal. Los sujetos del estudio fueron considerados en la perspectiva del Interaccionismo Simbólico, que valoriza el significado de los elementos del mundo como determinantes para la interacción. De acuerdo con los procedimientos metodológicos de la Teoría Fundamentada, se establecieron cinco elementos del paradigma del análisis: Causas, Contexto, Factores Intervinientes, Estrategias de acción/interacción y Consecuencias. El propósito de esta discusión es encontrar maneras por las cuales el cliente portador de enfermedad renal crónica enfrenta la diálisis peritoneal, en la eminencia de la realización de este método. Ante esta nueva situación, el cliente se inicia con un despertar, abandonando la idea de muerte y haciendo una clara distinción entre la enfermedad renal crónica y la diálisis. Si antes, las dos percepciones parecían solo una, el despertar presenta la diálisis peritoneal como el "anti-muerte", como un renacer para la vida.

Palabras clave: Enfermería. Diálisis. Cuidados de Enfermería

${ }^{1}$ Enfermeiro. Mestre pela EEAN-UFRJ. Especialista em nefrologia pela UGF. Possui Residência de Enfermagem em nefrologia pelo HUPE-UERJ. Rio de Janeiro-RJ. Brasil. Email: felipe-ks@uol.com.br,2Professora da Escola de Enfermagem Anna Nery/Universidade Federal do Rio de Janeiro. Membro do Núcleo de Pesquisa Fundamentos do Cuidado de Enfermagem. Coordenadora do Curso de Enfermagem - Campus Macaé-RJ. Brasil. Email: glauciavaladares@ig.com.br 


\section{INTRODUCÃO}

Dado o crescimento significativo do número de pessoas acometidas pela doença renal crônica (DRC) no Brasil e no mundo, faz-se relevante pensar e discutir as questões próprias a essa parcela da população. Em nosso país, as estatísticas disponíveis são alarmantes: o número de clientes mantidos em programa de diálise é superior a 70 mil pessoas. Dentre os brasileiros que fazem diálise, $53 \%$ situam-se na região sudeste e $20 \%$, na região nordeste. Entre os anos de 2005 e 2006, a prevalência no Brasil foi de 383 pessoas/milhão de habitantes. A mortalidade pela DRC chegou a $13 \%$ ao ano em 2005 e o custo do tratamento chega a 1,6 bilhões de reais/ano, praticamente $10 \%$ de toda a verba destinada a hospitais, clínicas, medicações e profissionais de saúde pública.

Esta discussão é parte integrante de uma dissertação de mestrado, intitulada: 0 enfrentamento do cliente portador de doença renal crônica mediante 0 início da diálise peritoneal - reflexões para o cuidado de enfermagem. Esta, vinculada ao Núcleo de Fundamentos do Cuidado de Enfermagem (NUCLEARTE) da Escola de Enfermagem Anna Nery da Universidade Federal do Rio de Janeiro (EEAN-UFRJ) - defendida e aprovada em dezembro de 2009. 0 objeto de estudo da referida disser tação foi o significado do enfrentamento do cliente portador de doença renal crônica mediante 0 início da diálise peritoneal (DP).

A relevância da discussão proposta reside na oportunidade de ampliar e consolidar o cuidado de enfermagem ofertado ao cliente em diálise peritoneal. 0 cuidado possui uma perspectiva técnica, mas também um significativo nível sensorial por implicar no encontro entre pessoas: quem cuida e quem é cuidado. ${ }^{2}$ Assim, se por um lado o cuidado implica em reações fisiológicas, por ser desenvolvido em um corpo dotado de órgãos sensoriais, há também uma série de emoções desencadeadas a partir de uma dimensão subjetiva, onde se dá o encontro de dois seres humanos.

Neste recorte pretende-se discutir a vivência do cliente ao ser encaminhado para a diálise peritoneal, ou seja, o impacto primeiro após receber a notícia de que será necessário realizar algum método de substituição da função renal. Considera-se que neste momento, a opção (ou a indicação médica) já está direcionada para a realização da diálise peritoneal.

\section{OBJ ETIVO}

Conhecer as formas pelas quais o cliente portador de doença renal crônica enfrenta a diálise peritoneal na iminência de realização deste método.

\section{REFERENCIAL TEÓRICO}

Para a concepção de indivíduo e de enfermagem em foco, foi escolhido o Interacionismo Simbólico, pois que este referencial valoriza o significado que o ser humano atribui às suas experiências. Por outro lado, também sublinha-se essa concepção teórica por ser aquela que considera o sujeito imerso em um mundo onde as relações sociais se estabelecem a partir das múltiplas representaç̃̃es. ${ }^{3}$

0 interacionismo simbólico distingue-se em relação às demais abordagens, pois dá uma importância axiomática ao sentido que as coisas têm para a definição do comportamento humano. Diferencia-se, ainda, por entender o sentido das coisas como emergindo do processo interativo entre os indivíduos e o seu próprio universo.

0 interacionismo simbólico afirma que os seres humanos estão relacionados às coisas, aos objetos, às pessoas e aos demais elementos do seu universo com base no significado que estes têm para eles próprios, o qual surge no e do processo interativo social que o indivíduo estabelece com outros seres humanos. Esses significados, que qualificam o simbólico, são constantemente revisitados e manipulados, sendo modificados por meio de um processo interpretativo utilizado pela pessoa ao lidar com as coisas que encontra. ${ }^{4}$

\section{REFERENCIAL METOLÓGICO}

Em consonância com os preceitos do interacionismo simbólico, optou-se por seguir os procedimentos da Teoria Fundamentada nos Dados (Grownded Theory), metodologia originalmente desenvolvida por dois sociólogos, Barney Glases e Anselm Strauss. ${ }^{3}$

A Teoria Fundamentada nos Dados (TFD) é apresentada como um tipo de pesquisa interpretativa alocada como uma variação dentro do interacionismo simbólico, sendo que o foco da TFD é a evolução da experiência social. Sua finalidade maior é gerar explicações para os fenômenos por meio da fundamentação na realidade. ${ }^{5}$

Ao utilizar a TFD é possível compreender os processos nos quais estão acontecendo os fenômenos, através de uma análise sistemática e da busca pela compreensão em profundidade. ${ }^{6}$ Esses fenômenos, por sua vez, emergem da realidade, e a TFD, por assim dizer, propõe que essas experiências possam retornar à mesma realidade sob a forma de uma Teoria.

A TFD permite gerar teorias explicativas a partir dos dados obtidos, analisados e comparados de maneira sistemática e concomitante. Essa metodologia vem sendo utilizada em diversos estudos indutivos de enfermagem e abre caminhos, propicia e orienta os pesquisadores em estudos interacionistas. É um processo de análise e interpretação de dados bastante complexo, que requer envolvimento constante e consome tempo e energia do investigador.? 
Estudiosos da metodologia ${ }^{8}$ desenvolveram uma estrutura para a construir um paradigma explicativo que inclui os seguintes aspectos do fenômeno em questão: Condições causais; Condições intervenientes, Contexto, Estratégias de ação e interação e Consequências. Neste momento, deter-nos-emos na discussão das Causas do fenômeno, ou seja, o conjunto de eventos, incidentes e acontecimentos que levam à ocorrência ou desenvolvimento do fenômeno.

Todos os procedimentos realizados seguiram as normas preconizadas pela Resolução n 196/96, que trata das Normas de Pesquisa Envolvendo Seres Humanos. Foi solicitada autorização do Comitê de Ética em Pesquisa em um Hospital Universitário do Rio de Janeiro, que cadastrou a investigação sob o número 2343-CEP/HUPE. Os clientes abordados aceitaram participar da pesquisa de forma voluntária e 0 fizeram mediante a assinatura do Termo de Consentimento Livre e Esclarecido.
A coleta de dados foi realizada através da entrevista semiestruturada em profundidade e da observação participante assistemática. Os depoimentos foram gravados em arquivo digital para posterior transcrição e análise.

Não foi instituído um número predeterminado de entrevistas. Os dados foram coletados e, na medida em que os mesmos foram preparados para análise, emergiu a necessidade de complementar as categorias existentes com outros dados. De tal modo que num contínuo analítico chegou-se ao total de oito depoentes assim identificados: Azul, Vermelho, Rosa, Roxo, Laranja, Preto, Marrom e Verde.

Um tipo de recurso visual utilizado para a organização dos dados foram os diagramas. Diagramas são representações gráficas que permitem a visualização do fenômeno, com vistas à melhor compreensão do mesmo. ${ }^{8} \mathrm{~A}$ seguir é apresentado o diagrama referente às causas do fenômeno estudado.

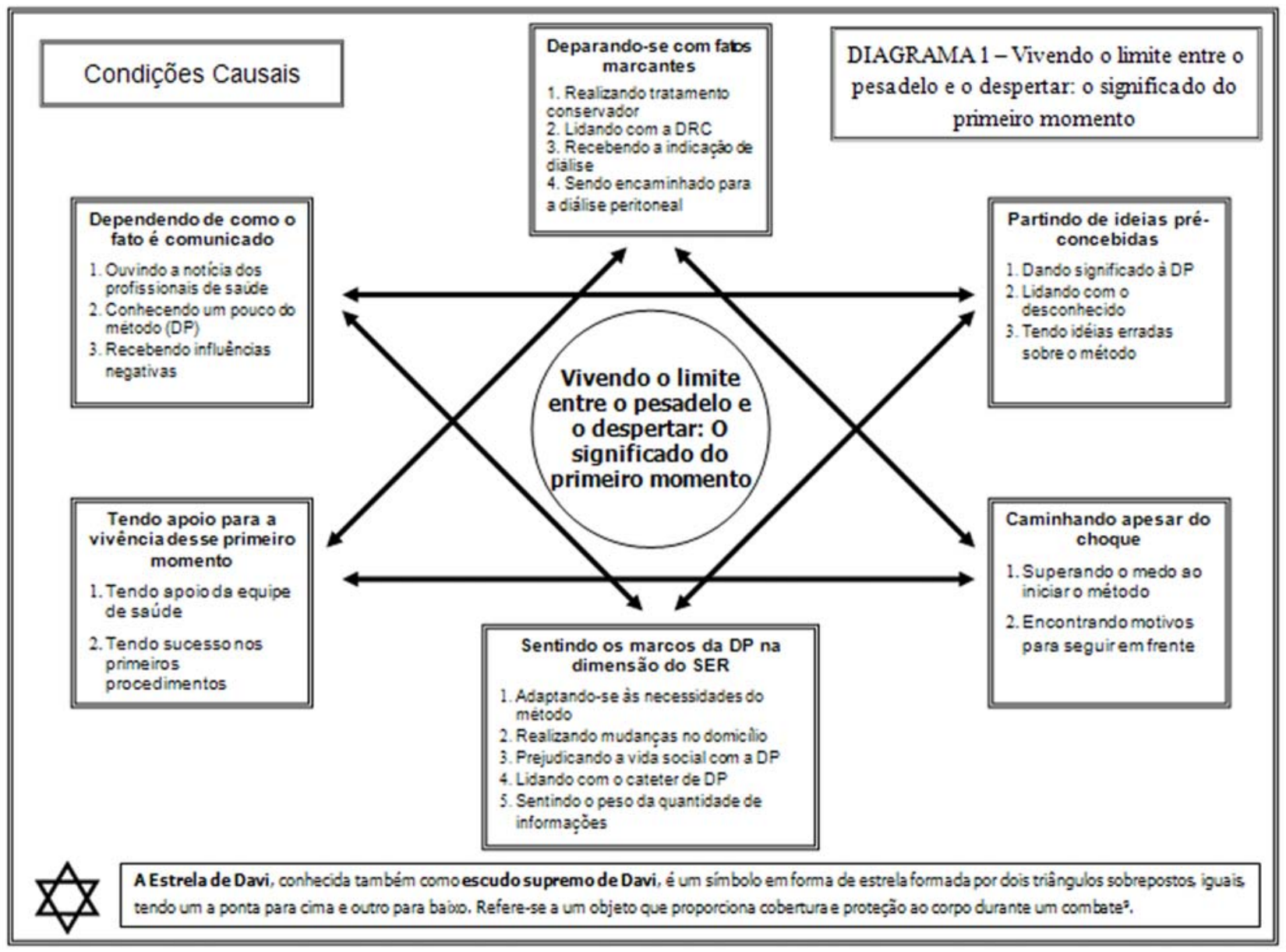

\section{RESULTADOS}

0 grupo amostral desta pesquisa incluiu 8 clientes em diálise peritoneal sem a realização de hemodiálise previamente. 0 perfil dos entrevistados incluiu 5 clientes do sexo feminino e 3 do sexo masculino, com idades que variaram entre 27 e 80 anos. Todos os clientes realizavam diálise peritoneal em um período inferior ou igual a um ano.
No processo de análise relacionado às condições causais destacaram-se as seguintes categorias: "Deparando-se com fatos marcantes"; "Dependendo de como o fato é comunicado"; "Partindo de ideias pré-concebidas"; "Sentindo os marcos da DP na dimensão do SER"; "Tendo apoio para a vivência desse primeiro momento" e "Caminhando apesar do choque".

Deparando-se com fatos marcantes - Com o inevitável avançar da doença renal, o indivíduo apresenta os primeiros 
sinais e sintomas, tendo que procurar o serviço apropriado para 0 atendimento de saúde. 0 cliente se depara com a notícia de que sua função renal está em níveis incompatíveis com a sobrevida humana e que, por isso, precisa realizar a diálise para manter-se vivo. Ao receber a indicação de diálise, ele vivencia o choque, conforme o depoimento que se segue:

Eu vim fazendo o tratamento da doutora cardiologista [...] Ela pediu exames de sangue [...] Mas ela viu que a ureia e a creatinina estava tudo muito alto... Foi quando me encaminhou pra fazer ou a hemodiálise ou a diálise peritoneal. Aíeu fiquei sem chão. AZUL

Alguns clientes são marcados pelo medo da morte ou de precisar realizar a diálise na emergência, no caso de urgência dialítica. 0 tom impositivo do profissional se confunde com outras dificuldades desse momento, de modo que a indicação para a diálise por vezes surge como um ultimato.

E ele [o médico] me dizia: "Você tem que fazer, porque se você não fizer você vai morrer... Ou então se você passar mal, você vai fazer de todo jeito, porque a gente vai fazer em você". LARANIA

Acontece, contudo, que nem sempre o tempo é suficiente para que o cliente seja preparado de forma satisfatória para o início da diálise domiciliar. Nesses casos, além da notícia da necessidade da diálise, o cliente acaba entrando em urgência dialítica e inicia a diálise no hospital, sob risco de vida, caso não a aceite. Nessa situação, os clientes lidam com o temor de realizar o método, tentando postergar o tempo fora da diálise.

Aí eu fiz o exame de urgência e quando veio o resultado para poder confirmar, aíjá estava com quatro e alguma coisa... Eaí ela falou para mim: Se o potássio estiver alto, você vai ficar. MARRON

A realidade se transforma e o momento seguinte exige formas de lidar com a notícia que acaba de receber. A perspectiva até então remota torna-se realidade palpável, necessária, e algumas vezes, urgente.

Dependendo de como o fato é comunicado-Pensando sobre a perspectiva do cliente que vem fazendo o acompanhamento ambulatorial para postergar a indicação de diálise, o momento em que recebe a notícia é bastante delicado.

Ao analisar o momento em que a indicação da diálise é comunicada ao cliente, há que se considerar as duas faces de uma mesma situação. A primeira consiste no fato de que a diálise é inevitável e, portanto, também é inevitável comunicála ao cliente. Adiar o inadiável seria uma atitude eticamente condenável, pois colocaria em risco a vida dos clientes.
No entanto, a segunda perspectiva é que o fato de ser inevitável não torna a aceitação da diálise mais fácil. Nesse momento, entram em cena todos os mitos, os receios, as preocupações, as incertezas, as frustrações e demais sentimentos com relação ao futuro.

É relevante pensar na equipe de saúde como veículo das informações a respeito da necessidade de diálise, agravantes e atenuantes. A equipe de saúde é quem informa sobre a iminência da necessidade de diálise. Os clientes referem esse momento como sendo de muita fragilidade e no qual a postura dos profissionais parece ter extrema relevância.

A pessoa sabe que tem um problema que vai ter que levar para o resto da vida. Ele não ser tratado como apenas mais um na estatística é muito importante! Muito! Entendeu? AZUL

A postura profissional no momento de comunicação da necessidade de realização da diálise deve ser considerada, dado o fato de que o cliente pode, num momento de desespero, negar a diálise por não se sentir acolhido, expondo-se dessa forma ao risco iminente de vida.

Ele só disse isso: "O senhor tem que fazer hemodiálise, e tem que procurar o SUS" [...] Aí eu falei: "Pô, esse cara já me largou na linha! O trem vem passando e vai me atropelar". Eu falei: "Não, não vou fazer mesmo!" [...] Eu vou ser sincero: eu só aceitei fazer isso mesmo, porque eu conhecio Dr. J. e ele me passou segurança pelo modo de falar. AZUL

Partindo de ideias pré-concebidas - As ideias préconcebidas manifestam-se geralmente na forma de atitudes discriminatórias, pejorativas ou de desconfiança em relação a algo ou alguém. Isso provém em grande parte do desconhecimento a respeito do ponto em questão. Indubitavelmente, pesam muito nesta postura os significados que o indivíduo construiu ao longo de sua existência.

Alguns clientes descrevem a diálise peritoneal como algo "horrivel", pois em geral os sujeitos comparam a nova realidade com a realidade que possuíam antes de serem portadores de doença renal crônica, quando tinham plena liberdade para se alimentar, se locomover e quando não precisavam conviver, dentre outras coisas, com a presença do cateter de diálise peritoneal no abdome. A diálise significa para eles, um novo mundo dotado de grande complexidade e restrições, suscitando comparações extremas:

[Quando eu ia montar a diálise] Eu só dizia para ele assim: "Filho! Vamos para a guerra!" ROSA 
Se por um lado, o conhecimento destorcido do que seja a diálise peritoneal atrapalha o seu processo de enfrentamento, de forma semelhante, há situações nas quais os clientes acabam lidando com o desconhecido no processo para a aceitação do método. Assim, o desconhecido deixa espaço para que surjam ideias por vezes mais perversas do que a própria realidade, que oprimem o sujeito, enchendo-o de insegurança. 0 desconhecido faz com que o indivíduo construa seus significados tendo como base os elementos concretos presentes em seu cotidiano. 0 evento então mitificado toma vultos assustadores, provocando até mesmo desespero.

Achava que eu ia morrer mesmo. Para você ver o pouco conhecimento que eu tinha sobre isso, né? LARANJA

Por vezes, os sujeitos acabam tendo ideias erradas sobre a diálise peritoneal, as quais podem dificultar ainda mais o seu caminhar. Uma ideia bastante comum é a ilusão de que ao iniciar o método, os clientes ficam inativos, incapacitados de realizarem tarefas simples e que perderão o convívio social. Esses conceitos são gerados por informações destorcidas e por pessoas que, em geral, têm associadas à doença renal outras morbidades incapacitantes.

[No início] eu achei que não seria mais capaz de realizar nada na minha vida. Não realizar as coisas materiais: o trabalho, a parte social [...] Eu estava me marcando como uma pessoa não mais apta a quase nada. Estava me sentido marcado como se eu tivesse uma deficiência. ROXO

Sentindo os marcos da DP na dimensão do "SER"- $\mathrm{Na}$ continuidade do processo de preparação do sujeito para a DP, muitas são as necessidades de adaptação para a realização do método. Essas transformações vão desde as restrições alimentares e de ingesta hídrica, passando pela adaptação na vida social, por mudanças corporais, até as adequações recomendadas no domicílio.

Na percepção dos clientes que ingressam no programa de diálise peritoneal, essas transformações constituem-se num montante significativo de informações, capaz de intimidá-lo e alterar o seu modo de viver, como se não pudessem realizar nenhuma de suas tarefas cotidianas.

Muita coisa muda! Muita coisa mesmo [...] Muda o modo de você viver. AZUL

Me passou pela cabeça de que a princípio eu tinha que mudar a minha vida... Que eu não poderia mais beber, que eu não poderia mais comer... Que eu não poderia nada! MARRON

Uma restrição que marca uma considerável parte dos sujeitos é o fato de ficarem limitados quanto ao banho de imersão, devido à presença do cateter de diálise peritoneal na superfície do abdome. Dessa forma, o banho de praia passa a ser algo descartado do cotidiano dos clientes, pelo potencial risco de contaminação através da água.

Só lamento não poder ir à praia mais... Pegando sol debaixo da barraca... Mas não vou poder fazer. AZUL

Todas as dimensões cotidianas parecem ser afetadas com o início da diálise, de tal modo que o sujeito opta por manter ou priorizar atividades que considera essenciais em sua vida. Na realidade, os horários realmente ficam mais restritos com o início da diálise. Associado a isso, outras morbidades e 0 avançar da idade fazem com que os clientes reduzam seu ritmo de vida, mantendo apenas algumas de suas atividades fundamentais.

Mudou, porque eu já não saio mais tanto conforme eu saía antes, a não ser para a igreja. PRETO

A permanência contínua de um cateter sobre a parede abdominal parece influenciar especialmente a relação desses clientes com os demais no mundo ao seu redor. Desde o primeiro instante, o cateter parece marcar a trajetória do indivíduo em diálise peritoneal, a começar pela cirurgia para o implante do mesmo.

Ai, eu achei horrivel [implantar o cateter]... Dor? Eu senti muita dor. Eu passei quase um mês de cama. Muita dor mesmo! É porque o cateter machucava lá dentro. LARANIA

Para as mulheres, a questão da autoimagem parece ter um peso ainda maior. A presença do cateter soa como uma ameaça, como um elemento capaz de fazer com que a união com seu parceiro corra algum risco. Por outro lado, o cateter acaba impedindo que as clientes exerçam plenamente a sua sexualidade, por medo, vergonha ou insegurança.

No início eu até estranhei, né... Eu pensei: "Ah, o meu marido não vai me querer mais". [...] Até bem pouco tempo eu ainda ficava meio retraída. VERDE

Tendo apoio para a vivência desse primeiro momento - Ao receber a indicação de diálise e começar a conhecer os detalhes que cercam o método, é comum ao cliente sentir-se sozinho, como se aquele acontecimento o invadisse exclusivamente. 0 sentimento de solidão, de isolamento, toma conta de seus pensamentos. Nesse momento, o apoio emocional faz toda diferença, na forma como o cliente lida com esses sentimentos, perante a DP. 
A primeira perspectiva de diálise muitas vezes surge sobre a forma de urgência, na qual o cliente deve ser preparado para realizar hemodiálise. Quando o indivíduo pode ser preparado com calma, quando não corre risco de morte, a recomendação é que ele possa escolher o método. Nesse sentindo, a indicação de diálise vem acompanhada da difícil escolha entre dois tratamentos totalmente desconhecidos da maioria da população.

Daí ela [a enfermeira] conversou comigo, chamou a psicóloga... Aíme deu essas duas opções. MARRON

A dificuldade de aceitação dos clientes deixa os profissionais de saúde em situação extrema. Vários são os motivos que levam os indivíduos a negarem, fugirem ou postergarem 0 início da diálise, incluindo a falsa ilusão de que o tratamento não é realmente necessário. Isso considerando o fato de ainda possuírem diurese (às vezes em grande volume), ou ainda, pelo fato de não se sentirem doentes. Essa postura acaba forçando os profissionais de saúde a adotarem posturas rígidas, incisivas, que podem soar como agressivas ou grosseiras.

Eu procurei o [hospital] porque ela [a médica] foi taxativa: "Ou você procura o tratamento que tem que ser feito ou eu não te atendo mais!" VERMELHO

Os dados mostram que existem atitudes profissionais capazes de despertar confiança e acolhimento, sentimentos indicados a fortalecer o cliente no delicado momento em que recebe a indicação de diálise e no qual ele precisa tomar uma série de atitudes pessoais e providências gerais para a realização da diálise peritoneal.

O sentimento que veio realmente foi de cuidado, de ter certeza [...] Então na minha cabeça assim: Quem ama, cuida. VERMELHO

Da equipe de saúde, de uma forma geral, é esperado um comportamento solidário, acolhedor, diferenciado e individualizado. 0 aspecto técnico também é ressaltado em algumas falas, mas de uma forma secundária. A maior expectativa é em relação ao lado humano, à forma como os clientes serão recebidos e conduzidos durante o tratamento.

Mesmo que ao iniciar a diálise eles não tenham a magnitude da responsabilidade e do papel profissional do enfermeiro, essa noção vai sendo adquirida com o avançar dos treinamentos para o início da diálise domiciliar. Nesse sentido, 0 cliente passa pelo processo onde ele modifica o significado que o enfermeiro tem para ele, a partir da interação com este profissional.

Inicialmente eu achei que eu não precisaria de ninguém pra me ensinar... Bastaria eu ter tudo escrito, todos os procedimentos [...] Mas depois eu vique era imprescindivel que fosse uma pessoa firme naquilo que estava fazendo. ROXO

Dentre outros atributos essências à equipe de saúde, destaca-se uma expectativa de que a equipe seja segura e até mesmo "firme" em relação às atitudes junto ao cliente e à terapêutica. Os próprios clientes identificam sua resistência inicial para a diálise e acreditam que uma postura categórica seja imprescindível para a sua adesão terapêutica. Os dados mostram que a aceitação da diálise é processada no contato com o profissional de enfermagem.

Se fosse com outra equipe, mais frouxa, eu acho que eu teria desistido. Mas eu tive profissionais sérios e principalmente, nunca tive dúvidas com relação ao que estava sendo feito... Os procedimentos, as conversas, as ideias, tudo [...] E quem acabou me convencendo [a aceitar a diálise] foi a enfermeira. VERMELHO

Ao mesmo tempo em que a convivência com a equipe vai deixando suas marcas no caminhar do cliente que inicia a diálise peritoneal, vários procedimentos são realizados concomitantemente para a preparação desse indivíduo. Assim, percebemos os clientes tendo sucesso nos primeiros procedimentos.

Eu tive muita sorte... Eu não conhecia nada no hospital, nem ninguém [...] Daí eu dei muita sorte porque quem pegou o meu caso foi a [enfermeira do CAPD]. MARRON

Caminhando apesar do choque - Frente a todos os acontecimentos que cercam o início da diálise, os dados mostram que, de uma forma ou de outra, os clientes são capazes de organização emocional. A este ponto, apresentamos algumas formas que o indivíduo encontra para seguir em frente, caminhando apesar do choque.

É possível perceber os clientes que iniciam a diálise peritoneal superando o medo ao iniciar o método, de tal modo que os clientes fazem essa diferenciação utilizando termos como "no início...". Isto sugere que a convivência com o método faça o indivíduo repensar e "ressignificar" sua visão a respeito da diálise peritoneal, de tal forma que até a preocupação com a realização do método é amenizada. Medos passam a ser reconsiderados a partir do ponto em que os sujeitos se percebem capazes de cumprir a diálise sem dificuldades ou dúvidas.

É patente que os efeitos benéficos da diálise peritoneal passam a influenciar a forma como o sujeito percebe o método. Isso é proporcionado com o avançar do tempo no método, aspecto mencionado pelos clientes de forma muito peculiar, a qual merece uma atenção especial. 
Se por um lado a indicação de diálise assusta, amedronta e faz pensar no pior, o "tempo" mostra que isso tudo não é verdade. Assim, conforme o cliente em diálise convive com o método, ele não só percebe o que a diálise é, como se dá conta também do que a diálise não é. Portanto, ele percebe que a diálise não é o fim do mundo, o fim da vida, nem o fim de inúmeras possibilidades de convivência harmoniosa com o método.

Além da necessidade de saúde impulsionar a aceitação do método, o elemento humano tem uma grande importância nesse processo de aceitação. 0 aspecto interativo (relacional) destaca-se em diversos momentos, seja no meio familiar, seja entre os profissionais da diálise peritoneal. Nesse momento, a preocupação com a família também serve como apoio para continuar em frente.

Ainda não posso ir, porque o [meu filho] ainda está aí... Eeu fiquei pensando: Se eu morrer, o que é que vaiser [dele]? [...] Porque se vocêf fizer besteira, é uma vida inteira... Tudo que você ensinou para os filhos, ou o que você criou, vai embora... Numa atitude impensada, numa maluquice. MARRON

\section{CONCLUSÃO}

Uma vez deflagrada a necessidade de diálise, destacase a forma como o cliente recebe essa notícia. Neste momento, frustração, decepção e medo se coadunam gerando uma sensação de pesadelo, o qual o cliente tenta negar, mas do qual não pode se afastar, sob risco de morrer. 0 choque maior é nesse momento, diante das primeiras informações, as quais soam como ataques, transformados numa infindável dúvida pela ação do medo.

As incertezas do desconhecido, o estranhamento com a equipe de saúde, as características e as restrições do método e as ideias pré-concebidas, que por vezes o cliente trás consigo, são aspectos importantes e determinantes nesse primeiro momento. As emoç̃̃es, muitas vezes embotadas pelo choque ou pela ação do mim: um autocontrole socialmente esperado, de não se expressar para a equipe que o recebe, fazem com que mitos e ideias infundadas tomem um vulto ainda maior.

0 pesadelo vivenciado no primeiro momento dá lugar a um incipiente despertar com 0 amadurecimento das primeiras informações, com o acolhimento da equipe de saúde e a partir da distinção que deve ser assimilada: sendo a doença renal incompatível com a vida, pela falência progressiva dos rins, a diálise peritoneal caminha no sentido oposto, restaurando o equilíbrio hidroeletrolítico e homeostático.

0 acolhimento é descrito como um elemento fundamental no momento do choque. 0 amparo repercute de forma positiva, ainda que nem tudo esteja absolutamente claro para esse cliente. 0 fato de sentir-se desamparado não apenas aumenta o sofrimento, mas também pode dificultar o ingresso do cliente no método, o que, em última análise, oferece risco à sua própria vida.

Ao caminhar no método, a recuperação da situação clínica e o fato de perceber que o tratamento não o tornaria inútil servem para angariar forças e continuar o tratamento dialítico. É uma forma diferente de ver a diálise, proporcionada pela convivência inicial com o método. Nessa nova situação, a diálise deixa de ser algo inutilizante e assume uma forma libertadora, capaz de aumentar o desejo de viver.

Quando o cliente acometido pela doença renal crônica conhece a diálise peritoneal, essas duas entidades formam como que um único ente: doença e método. 0 significado da doença renal é muito próximo ao significado da diálise. A doença leva à diálise e leva a crer que é uma mera continuação dela. Nesse momento, não existe distinção entre a doença e a diálise, e, nesse contexto, se a doença pode levar à morte, também a diálise poderá. Neste sentido, a diálise surge como pesadelo, como o pior possível, já que a mor te extingue qualquer outra possibilidade.

Enfrentando essa nova situação, o cliente parte para um novo despertar, deixando o pesadelo, abandonando a ideia de morte e passando a fazer uma distinção clara entre a doença renal crônica e a diálise peritoneal. Se antes as duas coisas pareciam uma só, o despertar apresenta a diálise peritoneal como a antimorte, como a um renascer para a vida.

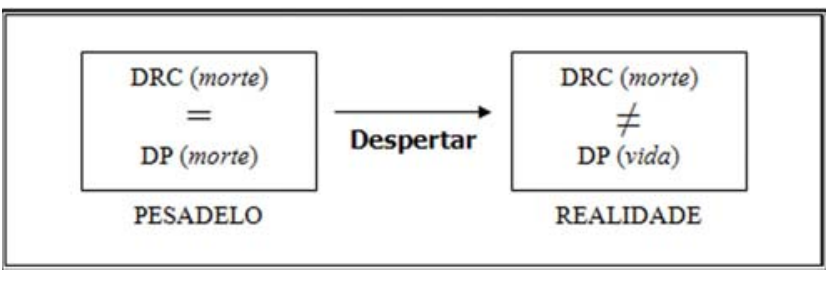

\section{REFERÊNCIAS}

1. Fráguas G, Soares SM, Silva PAB. A família no contexto do cuidado ao portador de nefropatia diabética: demandas e recursos. Esc Anna Nery. 2008 jun; 12(2):271-77.

2. Ferreira MA, Figueiredo NMA, ArrudaA, Alvim NAT. Cuidados fundamentais na ótica do cliente: uma contribuição para a enfermagem fundamental. Esc Anna Nery. 2002 dez; 6(3):387-96.

3. Dupas G. et al. A importância do interacionismo simbólico na prática da enfermagem. Rev Esc Enf USP 1997 ago; (31)2: 219-26.

4. Blumer H. Symbolic interactionism: perspective and method. Englewood Cliffs, NJ: Prentice-Hall; 1969. p. 208.

5. Cassiani SB, Caliri MHL, Pelá NTR. A teoria fundamentada nos dados como abordagem da pesquisa interpretativa. Rev Latino-am Enfermagem 1996 dez; 4(3): 75-88. 
6.Valadares GV. A formação profissional e o enfrentamento do conhecimento novo: a experiência do enfermeiro em setores especializados. Rio de Janeiro(RJ): UFRJ/ EEAN 2006. $290 \mathrm{f}$.

7. Bettinelli LA. A solidariedade no cuidado: dimensão e sentido da vida. Florianópolis(SC): UFSC/PEN; 2002, p. 204.

8. Strauss A, Corbin J. Pesquisa qualitativa: técnicas e procedimentos para o desenvolvimento da teoria fundamentada. $2^{\mathrm{a}}$ ed. Porto Alegre (RS): Artmed; 2008, p. 288.

9. Fine D. 0 que sabemos sobre o judaísmo? São Paulo (SP): Ed. Callis; 2007. p. 48. 